\title{
ASPECTOS ECONÔMICOS DA ADUBAÇÃO FOSFATADA PARA CULTURA DO MILHO'
}

\author{
Renato de Mello Prado ${ }^{2,4 *}$; Francisco Maximino Fernandes ${ }^{3}$ \\ ${ }^{2}$ Pós-Graduando do Depto. de Solos e Adubos - FCAV/UNESP - Via de Acesso Prof. Paulo Donato Castellane s/n ${ }^{\circ}$, \\ CEP: 14870-000 - Jaboticabal, SP. \\ ${ }^{3}$ Depto. de Ciência do Solo e Engenharia Rural, FEIS/UNESP - Av. Brasil 56 - CEP: 15385-000 - Ilha Solteira, SP. \\ ${ }^{4}$ Bolsista FAPESP. \\ *Autor correspondente <rmprado@fcav.unesp.br>
}

RESUMO: Estudos econômicos da adubação fosfatada fazem-se necessários, em razão da sua participação expressiva no custo de produção da cultura do milho, especialmente em solos sob vegetação de cerrado e face à competitividade da atividade no mercado globalizado. Assim, objetivou-se avaliar alguns aspectos econômicos de modos de aplicação da adubação fosfatada a lanço e sulco simples comparados ao modo alternativo em sulco duplo, utilizando o híbrido de milho BR 3123. Os tratamentos foram constituídos pelos modos de aplicação em sulco duplo, sulco simples e a lanço nas doses: $0 ; 0,50 ; 0,75 ; 1,00 ; 1,25 ; 1,50$ vez a dose recomendada para adubação de manutenção para o milho, ou seja, $90 \mathrm{~kg}$ de $\mathrm{P}_{2} \mathrm{O}_{5} \mathrm{ha}^{-1}$. Para a análise, considerou-se o preço médio da década de 90 para a tonelada do milho e do superfosfato triplo em $R \$ 189,33$ e $\mathrm{R} \$ 494,32$, respectivamente, e o custo operacional total de $\mathrm{R} \$ 752,90 \mathrm{ha}^{-1}$. O aumento das doses de adubo fosfatado, em geral, incrementou a produção, o valor da produção e a receita líquida por hectare; a aplicação do adubo fosfatado a lanço não se mostrou viável economicamente; o modo alternativo em sulco duplo permitiu maior receita líquida e uma relação benefício/custo 17,7\% superior, em relação ao sulco simples. Palavras-chave: Zea mays, superfosfato triplo, fósforo, benefício/custo, rentabilidade

\section{ECONOMIC ASPECTS OF PHOSPHORUS APPLICATION TO THE CORN CROP}

\begin{abstract}
Phosphorus has an expressive participation in corn crop production costs, especially for the Brazilian 'cerrado' soils. The economic aspects of this practice must be evaluated, mainly in the case of a competitive global market. Therefore an assessment of certain economic aspects related to the application forms of phosphorus was made. Cast and single furrow application methods were used in comparisson to the alternative double furrow practice. The BR 3123 hybrid corn was used. Treatments consisted of the P application modes in double furrow, single furrow and cast, at the levels of: $0 ; 0.50 ; 0.75 ; 1.00 ; 1.25 ; 1.50$ of the recommended rates for corn $\left(90 \mathrm{~kg}\right.$ of $\left.\mathrm{P}_{2} \mathrm{O}_{5} \mathrm{ha}^{-1}\right)$. For the analysis average prices in force during the 1990's of one ton of corn and one ton of triple superphosphate were considered (US $\$ 86.06$ and US $\$ 224.69$, respectively), and the total operating cost of US\$342.22 ha-1. In general the increase of the phosphorus rate boosted the yield and the net income per hectare; the cast fertilizer aplication by hand proved to be economically unfeasible. The double furrow treatment resulted, on the average, in a higher net income and a cost/benefit ratio exceeding by $17.7 \%$ that of the single furrow application mode.

Key words: Zea mays, triple superphosphate, phosphorus, cost/benefit, profitability
\end{abstract}

\section{INTRODUÇÃO}

Nos últimos anos, a atividade agrícola tem sofrido profundas modificações em razão do aumento do custo de produção com reflexos na rentabilidade da cultura, especialmente em grãos como o milho. A adubação é reconhecidamente o fator que mais afeta a produtividade e a sustentabilidade da atividade, de modo que o consumo de adubo pela cultura do milho no País tem crescido acentuadamente nos últimos anos, principalmente em função do aumento por unidade de área, porém o nível ainda é baixo, de modo que a participação do custo médio da adubação (NPK) na receita bruta média da cultura do milho é de, aproximadamente, $24 \%$, embora maior quando comparada a algumas culturas como arroz e soja (Tsunechiro \& Ferreira, 1996).

Dentre os nutrientes presentes nos fertilizantes, talvez o fósforo se constitua um dos mais limitantes para a cultura do milho, especialmente em solos sob vegetação de cerrado, que apresentam, em geral, baixo teor de fósforo disponível e reação ácida. Estas características, aliadas às altas taxas de sorção do fósforo, têm sido consideradas as limitações mais severas para a utilização destes solos no processo produtivo e para o aumento da produtividade, já que se 
fazem necessárias aplicações de altas doses de fósforo (Lopes, 1984). Ressalta-se, ainda, que os fosfatos são recursos naturais não renováveis, escassos e sem sucedâneos, devendo, portanto, ter utilização eficaz. Neste sentido, a ciência do solo tem estudado diferentes modos de aplicação do adubo fosfatado, especialmente a aplicação a lanço em área total e a localizada no sulco de semeadura, objetivando avaliar a situação de melhor eficiência agronômica.

A adubação a lanço permite maior contato do fertilizante com o solo, possibilitando elevada sorção do $P$ e reduzindo $o$ aproveitamento do elemento pela planta. Por outro lado, para diminuir a sorção, utiliza-se a aplicação localizada e, como conseqüência, pequena porção do sistema radicular entra em contato com o fósforo proveniente do adubo. Neste aspecto, tornam-se necessários estudos de modos de aplicação intermediários, para imprimir maior eficiência de uso do adubo fosfatado pelas plantas (Yost et al., 1979).

Apesar da reconhecida importância agronômica dos modos de aplicação do adubo fosfatado, existem poucos estudos econômicos comparativos envolvendo esta questão, relatados na literatura. A dimensão do retorno econômico da exploração comercial da cultura do milho está sustentada basicamente em três pontos: rendimento físico, custo de produção e preço do produto. Portanto, estudos econômicos da adubação fosfatada, no tocante ao modo de aplicação, têm efeito direto na participação expressiva nos dois primeiros fatores, através da otimização do seu uso, ou seja, utilização da menor quantidade possível de adubo e que resulte em aumento da produção da cultura. Quanto ao terceiro fator, preço do produto, apesar da importância deste na composição da rentabilidade do milho, Tsunechiro \& Miele Jr. (1999), estudando a variação dos preços e da produção do milho, nos anos de 1992-98, na safra normal, observaram menor variação dos preços quando comparada com a produção do milho, na mesma época, indicando que o risco de mercado foi menor que o risco de produção. Portanto, a rentabilidade do milho apresenta maior dependência do custo de produção e do rendimento físico do que propriamente do preço do produto. Sendo o custo de produção o fator em que o agricultor tem controle mais efetivo (Vitti \& Favarin, 1997).

A alta relação retorno/investimento (ou benefício/ custo) e o aumento da produtividade decorrentes de práticas de adubação adequadas têm, também, profundas implicações ambientais, haja vista a redução da necessidade de aberturas de novas fronteiras agrícolas para maior oferta de milho no mercado (Lopes, 1994).

Assim, o presente trabalho objetivou analisar alguns aspectos econômicos de modos de aplicação de adubos fosfatados a lanço e em sulco simples, comparados ao modo alternativo em sulco duplo, visando à melhor relação benefício/custo para a implantação da cultura do milho na região do Cerrado.

\section{MATERIAL E MÉTODOS}

O experimento foi desenvolvido no Município de Uberaba (MG), na Agropecuária Nossa Senhora Aparecida, num LATOSSOLO VERMELHO Aluminoférrico, conforme classificação da Embrapa (1999). Suas características químicas eram: matéria orgânica = $25 \mathrm{~g} \mathrm{dm}^{-3} ; \mathrm{pH}$ em $\mathrm{H}_{2} \mathrm{O}=6,2 ; \mathrm{P}$ - Mehlich-1= $5 \mathrm{mg} \mathrm{dm}^{-3}$; $\mathrm{K}=0,9 ; \mathrm{Ca}=30 ; \mathrm{Mg}=7 ; \mathrm{H}+\mathrm{Al}=21 \mathrm{mmol}_{\mathrm{c}} \mathrm{dm}^{-3} \mathrm{e}$ $\mathrm{V}=64 \%$.

O preparo do solo constou de uma gradagem pesada, seguida de escarificação e de duas gradagens de nivelamento. $\mathrm{Na}$ área do experimento, a cultura anterior foi a soja de ciclo tardio, durante cinco anos agrícolas consecutivos.

Os tratamentos estudados em blocos ao acaso, com quatro repetições, foram constituídos pelo esquema fatorial $3 \times 5$, sendo três modos de aplicação do adubo fosfatado (sulco duplo, sulco simples e a lanço) e cinco doses de adubação fosfatada 0,$50 ; 0,75 ; 1,00 ; 1,25 ; 1,50$ vez a dose recomendada para a adubação de manutenção, ou seja, $90 \mathrm{~kg}$ de $\mathrm{P}_{2} \mathrm{O}_{5}$ ha ${ }^{-1}$ (Comissão de Solos do Estado de Minas Gerais, 1989). Utilizou-se, como fonte de $\mathrm{P}$, o superfosfato triplo granulado (44\% de $\left.\mathrm{P}_{2} \mathrm{O}_{5}\right)$.

A adubação básica consistiu da aplicação a lanço, trinta dias antes da semeadura, de $115 \mathrm{~kg}$ de $\mathrm{K}_{2} \mathrm{O}$ ha $^{-1}$ com o objetivo de saturar $4 \%$ da CTC com potássio; $300 \mathrm{~kg}$ de gesso agrícola por ha, como fonte de enxofre; $40 \mathrm{~kg}$ de óxido silicatado (FTE BR12) por ha, como fonte de micronutrientes. A semeadura foi realizada com semeadora-adubadora com plataforma de 5 metros, equipada com quatro unidades semeadoras para a distribuição das sementes e oito unidades adubadoras para a distribuição do fertilizante com discos duplos. Essa semeadora-adubadora é a mesma comumente utilizada para culturas comerciais como soja, arroz e girassol entre outras, não havendo, assim, necessidade de aquisição de novos equipamentos ou adaptações e, conseqüentemente, não onerando o custo de produção da cultura implantada.

Quanto ao modo de aplicação do fertilizante fosfatado, os tratamentos foram constituídos da seguinte maneira: (a) sulco simples (modo convencional): referese à unidade adubadora ao lado da linha da semente, posicionada $5 \mathrm{~cm}$ ao lado e abaixo da semente. Com esta adubação, a faixa fertilizada no fundo do sulco foi de, aproximadamente, $4,5 \mathrm{~cm}$ de largura, ao passo que o espaçamento da cultura adotado foi de $0,90 \mathrm{~m}$, o que corresponde, aproximadamente, a $5 \%$ da faixa horizontal do solo; (b) sulco duplo (modo alternativo): consistiu de dois sulcos da unidade adubadora em cada linha da unidade semeadora, posicionados a $5 \mathrm{~cm}$ ao lado e abaixo da semente, de modo que a faixa fertilizada passou a ser o dobro da anterior, perfazendo, aproximadamente, $10 \%$ da faixa horizontal do solo; (c) a lanço: aplicação em área total, manualmente e com posterior incorporação a, aproximadamente, $15 \mathrm{~cm}$ de 
profundidade com grade niveladora (32 discos x 22"), perfazendo cerca de $100 \%$ da faixa do solo fertilizado.

As parcelas foram constituídas de oito linhas espaçadas de $0,90 \mathrm{~m}$ e $20 \mathrm{~m}$ de comprimento. Utilizouse o híbrido BR 3123 da Embrapa, semeado em 16-1095, com densidade populacional calculada em 55.000 plantas por ha. A adubação de cobertura foi realizada aos 22 dias após a semeadura, com $400 \mathrm{~kg}$ por hectare da fórmula 20-00-10.

Para obter o rendimento de grãos, foram colhidas, em 20 de abril de 1996, as quatro linhas centrais de cada subparcela, perfazendo uma área útil de $72,0 \mathrm{~m}^{2}$ e, em seguida, coletaram-se amostras para corrigir a umidade dos grãos para $0,13 \mathrm{~kg} \mathrm{~kg}^{-1}$.

Realizaram-se análises estatísticas de variância para a detecção de diferenças entre tratamentos, comparando-se as médias pelo teste de Tukey $(P<0,05)$.

Considerou-se o preço médio da década de 90 para a tonelada do milho e do superfosfato triplo em $R \$ 189,33$ e $R \$ 494,32$, respectivamente (Preços Agrícolas, 1999). O custo operacional de produção da cultura do milho (operações, insumos, administração e pós-colheita, exceto o custo do P) situou-se em $R \$$ 752,90 por hectare. Tomando o valor de $R \$ 11,36$ por saca de milho, comentado anteriormente, isto representou 66,28 sacas ha ${ }^{-1}$ ou 3,98 $\mathrm{t} \mathrm{ha}^{-1}$. Na verdade, esta produção é conhecida como ponto de equilíbrio, ou seja, a produção mínima suficiente para cobrir os custos operacionais. Portanto, para a obtenção dos incrementos líquidos de produção do milho, fez-se a diferença entre a produção total e o custo operacional, exceto o custo do P. A partir destes dados, calculou-se o valor líquido de produção (incremento líquido x preço do milho), a receita líquida (valor líquido da produção custo do $P$ ) e a relação benefício/custo (valor líquido da produção/custo do $P$ ).

\section{RESULTADOS E DISCUSSÃO}

Os estudos econômicos da adubação fosfatada tomaram como base 0 incremento líquido na produção de grãos de milho (acima do ponto de equivalência) em função das doses e dos modos de aplicação da adubação fosfatada (TABELA 1). Independentemente do modo de aplicação do adubo fosfatado, houve um incremento de 0,86 $\mathrm{t} \mathrm{ha}^{-1}$ para 3,27 $\mathrm{t} \mathrm{ha}^{-1}$ da menor para a maior dose de P. Portanto, o uso da adubação fosfatada permitiu uma produção acima do ponto de equivalência. Nestas circunstâncias, o preço do produto cobre o custo operacional médio, indicando que a atividade comercial de produção de milho tem condições econômicas de continuar produzindo, porém com rentabilidade dependente do volume da produção excedente.

O efeito agronômico positivo do $\mathrm{P}$ na produção do milho era esperado, conforme foi verificado por diversos autores (Hernandez \& Silveira, 1998), de modo que esta resposta do milho é explicada pelos benefícios da adubação no sistema solo-planta, porém estes efeitos não serão discutidos, e sim seus aspectos econômicos.

Houve diferença significativa quanto aos incrementos líquidos na produção do milho, na média das doses de $\mathrm{P}$, sendo o modo de aplicação em sulco duplo superior ao sulco simples que, por sua vez, foi superior à aplicação a lanço (TABELA 1).

Analisando separadamente os modos de aplicação, observa-se, pela Figura 1, que a utilização do adubo fosfatado a lanço apresentou um pequeno acréscimo no valor líquido da produção e alteração na receita líquida, porém sem significância. $O$ aumento das doses de fósforo e a falta do incremento significativo na receita líquida resultaram em efeito negativo na relação benefício/custo. Portanto, estes resultados sugerem que o uso do adubo fosfatado a lanço, nas dosagens estudadas, não apresenta viabilidade econômica para a cultura do milho. A ineficiência econômica da adubação fosfatada a lanço deveu-se à menor resposta na produção do milho, em razão da baixa dosagem utilizada (até $135 \mathrm{~kg}$ de $\mathrm{P}_{2} \mathrm{O}_{5} \mathrm{ha}^{-1}$ ), em detrimento da elevada capacidade de sorção de $P$ nesses solos oxídicos. Nestes solos, o teor de $\mathrm{P}$ é baixo, de modo que, para atingir maior produção, seria necessário aplicar $4 \mathrm{~kg}$ de

TABELA 1 - Incremento líquido na produção de grãos de milho, em função das diferentes doses e modos de aplicação da adubação fosfatada na cultura do milho.

\begin{tabular}{ccccc}
\hline \multirow{2}{*}{ Dose de $\mathrm{P}_{2} \mathrm{O}_{5}$} & \multicolumn{4}{c}{ Modo de aplicação } \\
\cline { 2 - 5 } & Lanço & Sulco simples & Sulco duplo & Média \\
\hline $\mathrm{kg} \mathrm{ha}^{-1}$ & $0,73^{(1)}$ & 1,05 & 0,81 & 0,86 \\
45 & 0,80 & 1,92 & 2,14 & 1,62 \\
67,5 & 0,84 & 2,66 & 3,42 & 2,31 \\
90 & 0,88 & 3,36 & 4,23 & 2,82 \\
112,5 & 1,17 & 3,64 & 5,00 & 3,27 \\
135 & $0,88 \mathrm{c}^{(2)}$ & $2,53 \mathrm{~b}$ & $3,11 \mathrm{a}$ & \\
Média & &
\end{tabular}

(1)Obtido pela diferença entre a produção total do tratamento em estudo, em t ha-1, e o custo total de produção, exceto o custo do $P$, calculado em $t$ ha $^{-1}$. (2) Letra igual na linha não diferencia pelo teste de Tukey $(P<0,05)$. 
$\mathrm{P}_{2} \mathrm{O}_{5}$ para cada \% de argila (Lopes, 1984). Como o presente solo apresenta $66 \%$ de argila, a dose estimada seria de $264 \mathrm{~kg} \mathrm{ha}^{-1}$ de $\mathrm{P}_{2} \mathrm{O}_{5}$, portanto bem acima da dose máxima aplicada.

Para o modo de aplicação em sulco simples, os resultados mostram que o valor líquido da produção aumentou significativamente em função das doses de adubo e, conseqüentemente, proporcionou maior receita líquida (Figura 2). Observa-se que, da menor para a maior dose de fósforo, o valor líquido da produção e a receita líquida variaram de $R \$ 198,80$ para $R \$ 689,16$ e de 148,39 para $R \$ 537,96$, respectivamente. No entanto, para as duas maiores doses, não houve diferença significativa tanto para o valor líquido da produção como para a receita líquida. Em função disso, observou-se, pela equação de regressão, que a dose de $100 \mathrm{~kg} \mathrm{P}_{2} \mathrm{O}_{5}$ resultou em maior relação benefício/custo, atingindo 0 valor de 5,24, ou seja, para cada Real investido, tem-se 5,24 Reais de retorno. Esta relação obtida no milho superou a cultura da soja cultivada em solos sob vegetação de cerrado, na qual Goedert \& Souza (1984), sob diferentes manejos, obtiveram a melhor relação benefício/custo de 1,87.

Este resultado mostra que, apesar de o rendimento físico e de o incremento líquido terem aumentado até na dose máxima de P (TABELA 1), não é interessante aplicar-se tal dose para se atingir a máxima eficiência econômica.

$\mathrm{Na}$ aplicação do fósforo em sulco duplo, da mesma forma que na aplicação em sulco simples, observou-se que o valor líquido da produção e a receita líquida aumentaram significativamente com as doses de fósforo (Figura 3) e que, da menor para a maior dose de fósforo, o valor líquido da produção e a receita líquida variaram de $R \$ 153,36$ para $R \$ 917,33$, e de $R \$ 102,96$ para $R \$ 771,79$, respectivamente. No entanto, para as duas maiores doses, não houve diferença significativa tanto para o valor líquido da produção como para a receita líquida. Esta falta de diferença nas maiores doses levou a relação beneficio/custo a apresentar um comportamento quadrático, na qual, pela equação de regressão, a dose de $105 \mathrm{~kg} \mathrm{P}_{2} \mathrm{O}_{5}$ esteve associada à relação benefício/custo de 6,37 .

Estes resultados indicam que as doses de $\mathrm{P}$, que promoveram maior retorno econômico, tanto para o modo de aplicação em sulco simples como em sulco duplo, foram maiores que os $90 \mathrm{~kg}$ de $\mathrm{P}_{2} \mathrm{O}_{5}$ recomendados pelo órgão de recomendação de adubação oficial da região (Comissão de Solos do Estado de Minas Gerais, 1989); portanto, estes resultados sugerem que as doses de $P$ podem ser aumentadas sem que ocorra perda na eficiência econômica da atividade.

Cabe salientar que a interação significativa entre modos de aplicação e doses, cujos valores de $F$ $(P<0,01)$ foram 15,$0 ; 17,6 ; 17,3$ e 10,9 para as variáveis incrementos da produção, valor líquido da produção, receita líquida e relação benefício/custo, respectivamente, ocorreu em detrimento do efeito diferenciado dos modos de aplicação do $P$, sendo que a aplicação a lanço não promoveu efeito significativo nas variáveis valor líquido da produção e receita líquida, e, ainda, a relação benefício/ custo apresentou um efeito quadrático negativo com as doses de $P$ (Figura 1), enquanto, no modo de aplicação em sulco simples (Figura 2) e em sulco duplo (Figura 3), as doses de $P$ aumentaram significativamente 0 valor líquido da produção e a receita líquida, e, ainda, a relação benefício/custo apresentou um efeito quadrático positivo.

Comparando os dois últimos modos de aplicação de $\mathrm{P}$, observa-se que, na menor dose de $\mathrm{P}$, o modo em sulco simples apresentou a receita líquida de $R \$ 148,39$ (Figura 2), ao passo que o modo em sulco duplo foi de $\mathrm{R} \$ 102,96$ (Figura 3); portanto, o modo em sulco simples apresentou melhor comportamento. Assim, estes resultados sugerem que, em condições de baixo nível tecnológico, que utiliza doses próximas a $45 \mathrm{~kg}$ de $\mathrm{P}_{2} \mathrm{O}_{5}$ $\mathrm{ha}^{-1}$, o modo de aplicação em sulco simples é economicamente mais vantajoso. No entanto, para as

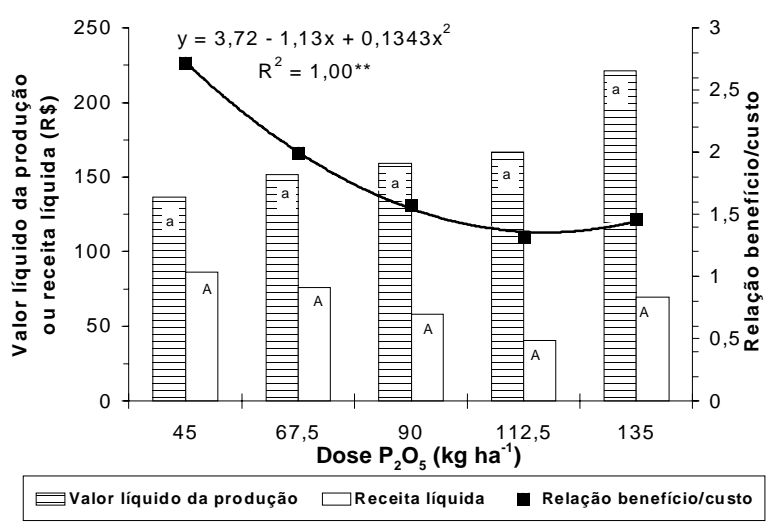

Figura 1 - Efeito da adubação fosfatada à lanço no valor líquido da produção de milho, na relação benefício/custos da produção e na respectiva receita líquida. (Dados médios de quatro repetições). Letras minúsculas comparam as médias do valor líquido da produção e a maiúsculas a receita líquida, pelo teste de Tukey $(P<0,05)$.

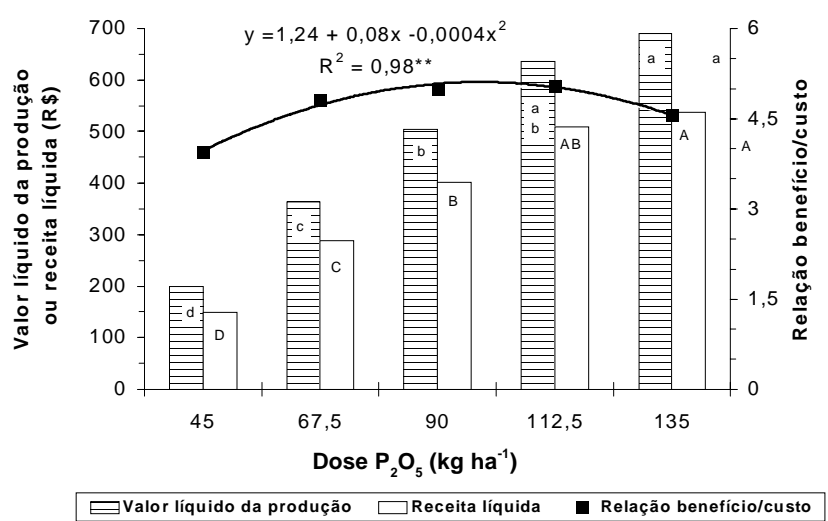

Figura 2 - Efeito da adubação fosfatada em sulco simples no valor líquido da produção de milho, na relação benefício/custos da produção e na respectiva receita líquida. (Dados médios de quatro repetições). Letras minúsculas comparam as médias do valor líquido da produção e a maiúsculas a receita líquida, pelo teste de Tukey $(P<0,05)$. 


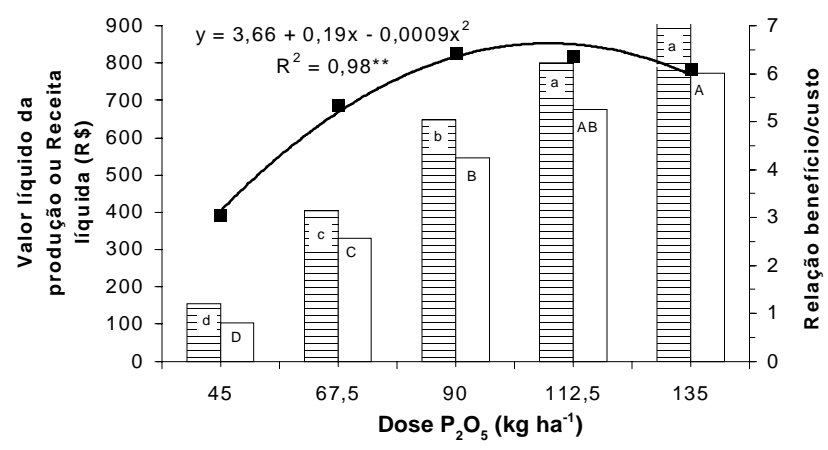

$\sqsubseteq$ Valor líquido da produção $\square$ Receita líquida $\square$ Relação benefício/custo

Figura 3 - Efeito da adubação fosfatada em sulco duplo no valor líquido da produção de milho, na relação benefício/custos da produção e na respectiva receita líquida. (Dados médios de quatro repetições). Letras minúsculas comparam as médias do valor líquido da produção e a maiúsculas a receita líquida, pelo teste de Tukey $(\mathrm{P}<0,05)$.

doses acima de $67,5 \mathrm{~kg}$ de $\mathrm{P}_{2} \mathrm{O}_{5}$ ha $^{-1}$, o modo em sulco duplo foi superior, atingindo, na maior dose, uma receita líquida de $R \$ 771,79$ (Figura 3) contra $R \$ 537,96$ em sulco simples (Figura 2); portanto, para níveis de tecnologia de médio a alto, que utilizem doses de 67,5 a $135 \mathrm{~kg}$ de $\mathrm{P}_{2} \mathrm{O}_{5}$ ha $^{-1}$, o modo de aplicação em sulco duplo apresenta melhor retorno econômico.

A superioridade do modo de aplicação em sulco duplo pode ser notada, também, na relação benefício/custo, pois, na melhor dose de P, o sulco simples apresentou uma relação benefício/custo de 5,24 (Figura 2) contra sulco duplo de 6,37 (Figura 3), representando $17,7 \%$ de diferença. Resultados semelhantes foram obtidos por Vasconcellos et al. (1986) em solos sob vegetação de cerrado os quais verificaram que o modo de aplicação intermediário do adubo fosfatado permitiu um retorno líquido $15 \%$ superior ao modo convencional no sulco de semeadura, na cultura do milho.

Os valores da relação benefício/custo para os dois últimos modos de aplicação de adubo fosfatado chegaram a superar a relação benefício/custo do calcário, para a qual Becker et al. (1990) encontraram um valor de 3,2. Portanto, estes resultados discordam de Raij \& Quaggio (1984) que colocam que o calcário seria o insumo agrícola de maior retorno econômico para a cultura do milho.

\section{CONCLUSÕES}

O aumento das doses de adubo fosfatado, em geral, incrementou a produção, o valor líquido da produção e a receita líquida por hectare.

A aplicação do adubo fosfatado a lanço não se mostrou viável economicamente.

O modo alternativo em sulco duplo permitiu, em média, em relação ao sulco simples, maior receita líquida e uma relação benefício/custo $17,7 \%$ superior.

\section{AGRADECIMENTOS}

À Agropecuária Nossa Senhora Aparecida, por ceder o espaço físico; e ao Prof.Dr. William Natale da FCAV/UNESP, pelas sugestões.

\section{REFERÊNCIAS BIBLIOGRÁFICAS}

BECKER, F.C.; FLORES, E.; RUSSOWSKI, R. Proposta de um Plano Nacional de Calagem - PLANACAL. São Paulo: ANDA, 1990. 19p.

COMISSÃO DE FERTILIDADE DO SOLO DO ESTADO DE MINAS GERAIS. Recomendações para o uso de corretivos e fertilizantes em Minas Gerais: $4^{a}$. aproximação. Lavras: CFSEMG, 1989. 159p.

EMPRESA BRASILEIRA DE PESQUISA AGROPECUÁRIA. Centro Nacional de Pesquisas de Solos. Sistema brasileiro de classificação de solos. Brasília: Embrapa, 1999. 412p.

GOEDERT, W.J.; SOUZA, D.M.G. Uso eficiente de fertilizantes fosfatados. In: SIMPÓSIO SOBRE FERTILIZANTES NA AGRICULTURA BRASILEIRA, Brasília, 1984. Anais. Brasília: EMBRAPA, 1984. p.255-289.

HERNANDEZ, R.J.; SILVEIRA, R.I. Efeito da saturação por bases, relação Ca:Mg no solo e níveis de fósforo sobre a produção de material seco e nutrição mineral do milho (Zea mays L.). Scientia Agricola, v.55, p.79-85, 1998.

LOPES, A.S. Solos sob "cerrado": características, propriedades e manejo. Piracicaba: Potafós, 1984. 162p.

LOPES, A.S. Uso de tecnologia moderna na preservação do meio ambiente. In: SIMPÓSIO NACIONAL DO SETOR DE FERTILIZANTES, 1., São Paulo, 1994. Anais. São Paulo: ANDA; IBRAFÓS, 1994. p.247-279.

PREÇOS AGRÍCOLAS. Caderno de estatísticas. Piracicaba: ESALQ/USP, n.157, p.36,26-27, 1999. Encarte

RAIJ, B.van.; QUAGGIO, J.A. Uso eficiente de calcário e gesso na agricultura. In: SIMPOSIO SOBRE FERTILIZANTES NA AGRICULTURA BRASILEIRA, 1, Brasília, 1984. Anais. Brasília: EMBRAPA, 1984. p.323-346.

TSUNECHIRO, A.; FERREIRA, C.R.P.T. Aspectos econômicos da adubação do milho no Brasil. Informações econômicas v.26, p.21-28, 1996.

TSUNECHIRO, A.; MIELE JR., C. Análise do risco da produção e do mercado de milho "safrinha". In: SEMINÁRIO SOBRE A CULTURA DO MILHO "SAFRINHA", 5., Barretos, 1999. Anais. Campinas: Instituto Agronômico, 1999. p.127-132.

VASCONCELLOS, C.A.; SANTOS, H.L.; FRANÇA, G.E.; BAHIA FILHO, A.F.C.; PITTA, G.V.E. Níveis, modos de aplicação e fontes de fosfatos na produção de milho. Pesquisa Agropecuária Brasileira, v.21, p.245-254, 1986.

VITTI, G.C.; FAVARIN, J.L. Nutrição e manejo químico do solo para a cultura do milho. In: FANCELLI, A.L.; DOURADONETO, D.(Ed.) Tecnologia da produção de milho Piracicaba: Publique, 1997.p.104-120.

YOST, R.S.; KAMPRATH, E.J.; LOBATO, E.; NADERMAN, G. Phosphorus response of corn on oxisol as influenced by rates and placement. Soil Science Society of America Journal, v.43, p.338-343, 1979.

Recebido em 09.06.00 